\title{
ALGORITMO PARA REDUÇÃO DE ERROS DE MEDIDAS EM POÇOS DE PETRÓLEO ATRAVÉS DE FILTRAGEM
}

\author{
Daiane Costa Guimarães \\ Universidade Federal de Sergipe (UFS) - Av. Marechal Rondon, s/n Jardim Rosa \\ Elze - CEP 49100-000 - São Cristóvão/SE \\ dayaned10@hotmail.com \\ Mayara Laysa de Oliveira Silva \\ Universidade Federal de Sergipe (UFS) - Av. Marechal Rondon, s/n Jardim Rosa \\ Elze - CEP 49100-000 - São Cristóvão/SE \\ laysamay@hotmail.com \\ Suzana Leitão Russo \\ Universidade Federal de Sergipe (UFS) - Av. Marechal Rondon, s/n Jardim Rosa \\ Elze - CEP 49100-000 - São Cristóvão/SE \\ suzana.ufs@hotmail.com
}

\section{Resumo}

As variáveis geradas durante uma perfuração de poços de petróleo, por sônicos introduzidos nos poços de petróleo equipados com sensores, são constituídas de um grande número de pontos onde se tem os valores georreferenciados. Nem todos os pontos coletados refletem as variáveis do perfis adequadamente, sendo comum a ocorrência de erros na coleta dos dados. A perfilagem é uma ferramenta fundamental na moderna operação de obtenção de variáveis de perfis em poços de petróleo, as quais dependem da disponibilidade de modelos confiáveis obtidos a partir do processamento de medições adquiridas em tempo real. Com o objetivo de filtrar os dados, fornecidos pela Petrobrás, implementados numa planilha Excel, foi analisado: DT, Profundidade, Nível Estratigráfico, Dcali, Vsh. Foi criado uma nova categoria Vsh_cat e o Dcali_cat. Os dados foram filtrados e verificamos uma melhora nos dados, reduzindo a quantidade de erros introduzidos durante a perfuração do poço.

Palavras-chave: Petróleo, Perfis, Filtragem, Perfuração.

\begin{abstract}
During an oil well drilling, sonics are introduced into the well. These sonics are equipped with a variety of sensors, what, generates a large amount of georeferenced data. Some of these data does not reflect properly on the profile variables, with data error during collection being usual. The profiling is an important tool in the current process of profile variable collection in oil well, and this tool depends on the availability of reliable models, which are obtained from the measurements acquires in real time. In order to filter this data, provided by Petrobras, presented in an Excel spreadsheet, we analysed the following variables: DT, Depth, Stratigraphic Leve, Dcali, Vsh. We created two new categories, Vsh_cat and Dcali_cat. Finally, we verified the filtered data and we noticed an improvement in the data, what reduced the amount of error introduced during the drilling of the well.
\end{abstract}

Keywords: Oil, profiles, filtering, drilling. 


\section{INTRODUÇÃO}

Conforme é sabido por todos que acompanham os aspectos relevantes de nosso planeta, sobretudo econômico, percebe-se que o petróleo é uma das fontes de energia mais importantes, a qual implica diretamente na sobrevivência de quase toda a totalidade da população mundial, gerando inclusive conflitos globais armados em busca da exploração das reservas existentes, de modo que se torna cada vez mais imperiosa a busca por meios que potencialize e maximize a produção desse bem cada vez mais escasso. Cada poço de petróleo perfurado custa milhões de dólares, por tal fator torna-se necessário um bom mecanismo de precisão e certeza sobre a localidade desses poços de petróleo procurando assim a redução de erros na pesquisa geológica e geofísica dos poços. (ALMEIDA, 2002)

Para a criação desse trabalho será utilizado à pesquisa bibliográfica como a principal forma de estudo. A técnica estatística usada será o método descritivo com o objetivo de identificar a existência de anomalias em observações ocorridas durante a perfuração de poços de petróleo.

Esse estudo objetiva construir um algoritmo para identificar os erros de medidas em amostras de uma base de dados oriunda de perfurações de poços de petróleo das unidades geológicas da Bacia Sergipe-Alagoas para melhorar e reduzir os erros na construção do perfil sônico sintético.

Torna-se indispensável a utilização da estatística para reduzir a quantidade de erros oriundos da perfuração de poços de petróleo, para um melhor sucesso do perfil sônico, através da filtragem dos dados que consiste de dados brutos que provêm diretamente das medições efetuadas pela broca, essas medidas são gravadas em programa específico para gerar depois o perfil sônico. Para essa redução de erro aplicaremos um algoritmo adaptado do desenvolvido por Menegatti e Molin (2004).

O referido estudo visa demonstrar os métodos aplicados para criação do algoritmo, como são abordados e qual referência aos poços de petróleo. A prospecção de petróleo, perfil sônico e medidas de descritivas serão citadas neste trabalho.

\section{REVISÃO TEÓRICA}

\subsection{PROSPECÇÃO DE PETRÓLEO}

A indústria do petróleo é por natureza uma indústria de intensidade de capital elevada. Antes de se produzir o petróleo, um grande volume de capital é necessário para a identificação do óleo e desenvolvimento dos campos. Entretanto, a fase de prospecção é caracterizada por riscos elevados. Podemos apontar os riscos geológicos implícitos à atividade mineral e os riscos políticos, em função de possíveis mudanças desfavoráveis e inesperadas nas condições institucionais nos países hóspedes. Apesar dos riscos associados, a busca de novas reservas é uma questão de sobrevivência para as empresas de petróleo (ALMEIDA, 2002).

A identificação de uma área favorável à acumulação de petróleo é realizada através de métodos geológicos e geofísicos, que, atuando em conjunto, conseguem indicar o local mais propicio para a perfuração. O programa desenvolvido durante a fase de prospecção fornece uma quantidade muito grande de informações técnicas (Almeida, 2002).

Para detectar a presença de petróleo para exploração, se faz necessário enviar ondas sonoras de choque pelo piso do oceano durante um determinado tempo, mas ainda assim é preciso escavar o poço para verificação. Para cuidar da tarefa, as empresas petroleiras enviam uma plataforma móvel de prospecção para realizar perfurações prospectivas no local. Algumas delas são instaladas em navios, outras precisam ser rebocadas ao local por embarcações. (FREUDENRICH, C. e STRICKLAND, J, 2001) 
Um programa de prospecção visa fundamentalmente a dois objetivos: (1) localizar, dentro de uma bacia sedimentar, as situações geológicas que tenham condições para a acumulação de petróleo; e (2) verificar entre estas bacias e situações geológicas, possuem mais chances de conter petróleo (PRESTRELO, 2006).

\subsection{PERFILAGEM}

As primeiras aplicações da perfilagem de poços foram realizadas na década de 20 para correlação de padrões similares de condutividade elétrica de um poço a outro, algumas vezes sobre grandes distâncias. Com o aperfeiçoamento e aumento das técnicas de aquisição, as aplicações começaram a ser direcionadas para avaliações quantitativas de reservatórios de hidrocarbonetos (LIMA, 2005)

A perfilagem é uma ferramenta fundamental na moderna operação de obtenção de variáveis de perfis em poços de petróleo.

As etapas de perfilagem geram um grande volume de informações sobre a espessura, profundidade e comportamento das camadas de rochas existentes nas vizinhanças do poço. (SILVA, 2006).

A perfilagem é o processo de traçar uma imagem visual ou perfil, em relação à profundidade,de uma ou mais propriedades das rochas perfuradas. Tais perfis são obtidos através do deslocamento contínuo de sensores de perfilagem dentro do poço. A perfilagem a poço aberto é feita antes da descida do revestimento de produção e tem como objetivo a identificação da litologia do poço, estimar a porosidade das rochas e detectar a presença de hidrocarbonetos leves ou gás (SILVA, 2006).

\subsection{PERFIL SÔNICO}

O perfil sônico é utilizado na construção de sismogramas sintéticos, que correspondem ao resultado da modelagem da resposta sísmica em determinada área e são obtidos usando-se um algoritmo próprio e tem por finalidade auxiliar na interpretação dos horizontes sísmicos, permitindo correlacionar esses horizontes com os níveis estratigráficos atravessados pelo poço perfurado, além de propiciar a criação de tabelas de conversão tempo vs profundidade, o que permite migrar toda uma interpretação sísmica, que está no domínio do tempo, para o domínio do espaço (profundidade).Como não é viável economicamente fazer uma aquisição do perfil sônico, na grande maioria dos poços antigos, principalmente em decorrência da parada da produção do óleo, para contornar a falta de informação, deve-se recorrer a outros meios para solucionar o problema. Uma das maneiras é utilizar métodos estatísticos que gerem um perfil sônico, dito sintético, para estabelecer estimativas das velocidades sísmicas das rochas ao longo dos poços (RUSSO, 2010).

O sismograma sintético é obtido da convolução de um pulso sísmico sintético com os coeficientes de reflexão. Os termos convolução e coeficiente de reflexão podem ser entendidos nas explicações contidas em Duarte (1997). Uma tabela que relacione tempo com profundidade tem que ser usada para a geração do sismograma sintético em tempo curva (TxP) de maneira a permitir a correlação sísmica/poço.

Figura 1 - Exemplo ilustrativo de um sismograma sintético. (A) coluna sedimentar. (B) impedância acústicas.(C) função refletividade. (D) reflexões individuais de cada interface. (E) traço sintético final. Conforme apresentado em Thomas (2001). 


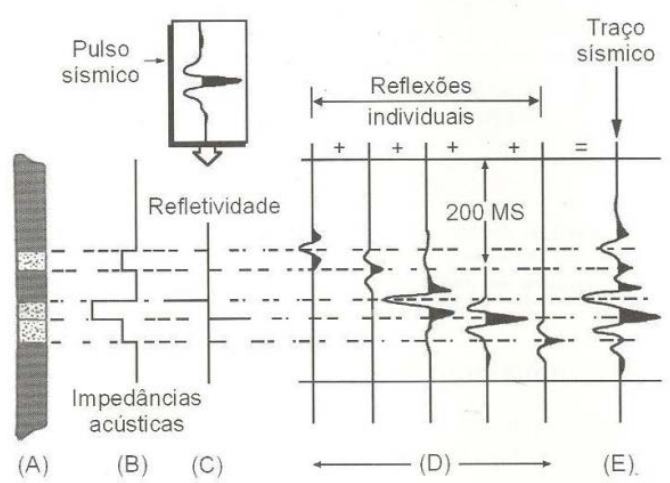

\section{Figura 1: Passos para geração de um sismograma sintético}

A principal importância do sismograma sintético é correlacionar os dados de poços, que estão representados no domínio do espaço com os eventos que aparecem nas seções sísmicas que estão no domínio do tempo (RUSSO, 2010).

A ferramenta sônica consiste, basicamente, no registro do tempo decorrido entre o momento em que um pulso sonoro compressional é emitido por um transmissor, montado em um mandril no interior do poço, até sua chegada a dois receptores distintos sobre o mesmo mandril. A diferença entre os dois tempos de chegada (transmissor - receptor perto T-RP e transmissor - receptor longe T-RL) é chamada de tempo de trânsito ou delay time (DT) (LIMA, 2005). Em sua tese (Lima, 2005) afirma que elevados tempos do DT podem representar fraturas, desmoronamentos ou até mesmo presença de gás no poço. (RUSSO, 2010)

O tempo de trânsito (DT) guarda uma relação direta com a porosidade da rocha. Quanto maior o DT, maior a separação entre os grãos, portanto, maior a porosidade, sendo a recíproca verdadeira. Consequentemente, a maior vantagem do perfil sônico provém da relação direta que existe entre o tempo de trânsito de uma onda sonora em uma rocha e a sua porosidade (Wyllie, 1956). Em sua tese (Lima, 2005) afirma que elevados tempos do DT podem representar fraturas, desmoronamentos ou até mesmo presença de gás no poço. (RUSSO, 2010)

\subsection{OUTLIERS}

Um dos passos a ser cumpridos por um pesquisador é a avaliação sobre os dados disponíveis, essa avaliação verifica o comportamento dos dados disponíveis e a qualidade dos mesmos. É comum ao estudar um banco de dados o pesquisador encontrar dados que se diferenciam do conjunto de dados analisados.

Segundo Figueira (1998) observações que apresentem um grande afastamento do restante do conjunto de dados, ou são inconsistentes; são comumente chamadas de outliers.

"Um outlier é caracterizado pela sua relação com as restantes observações que fazem parte da amostra. O seu distanciamento em relação a essas observações é fundamental para se fazer a sua caracterização. Estas observações são também designadas por observações "anormais", contaminantes, estranhas, extremas ou aberrantes.” (FIGUEIRA, 1998)

\subsection{ALGORITMO DE MENEGATTI E MOLIN}

Com o intuito de reduzir os erros existentes num mapa de produtividade, gerados na região dos Campos gerais do Paraná, Menegatti e Molin (2000) desenvolveram um algoritmo para remoção de erros em mapas de produtividade.

A partir de dados coletados automaticamente, os mapas de produtividade são elaborados, sendo um processo automático gerado a partir dos monitores de produtividade, assim pontos 
são gerados indicando sua localização. Os mapas de produtividade se baseiam então na disposição dos pontos de maneira ordenada (MACHADO et al 2004).

Para obter os dados, é preciso considerar o número de erros sistemáticos e introduzir na produção dos mapas, destes quais alguns serão eliminados por rotinas e a categorização em programas computacionais. O mapa de produtividade é fundamental para a agricultura de precisão, pois se tornou um suporte para a tomada de decisões, resultando num direcionamento dos investimentos (MACHADO et al 2004).

Define-se como agricultura de precisão uma abordagem de gerenciamento que leva em consideração a variabilidade espacial (e temporal) das lavouras buscando tirar proveito dessas desuniformidades sempre que elas forem relevantes (MOLIN, 2012).

Os erros apresentados nos mapas de produtividade podem levar a interpretações errôneas da variabilidade, daí a importância da análise dos dados e reduções dos seus erros. A eliminação dos dados discrepantes foi realizada com a utilização de uma planilha eletrônica e suas funções de lógica, os dados foram importados para a planilha sendo filtradospor meio do algoritmo criado. (GIMENEZ E MOLIN, 2004) No processo de Filtragem dos dados foram utilizados os dados brutos provindo dos monitores, assim, para uma melhor análise (MENEGATTI E MOLIN, 2003).

De acordo com Bazzi (2006) primeiramente os dados foram inseridos num Sistema de Informações Geográficas (SIG) para a retirada de erros grosseiros de posicionamento, representados por pontos fora do talhão. De uma forma geral e simplificada a metodologia utilizada por Menegatti e Molin segue os seguintes passos:

1) Colheita;

2) Geração dos arquivos-texto e arquivos do software utilizado;

3) Disponibilidade dos dados brutos;

4) Retirada dos erros grosseiros de posicionamento;

5) Retirada dos pontos com produtividade nula;

6) Retirada dos pontos com largura parcial da plataforma;

7) Retirada dos pontos com teor de água nula ou ausente;

8) Retirada de pontos com distância nula, realizada no SIG;

9) Remoção de pontos gravados durante o tempo de enchimento;

10) Remoção de pontos com produtividade discrepantes;

11) Dados reordenados;

12) Dados filtrados.

Para a remoção dos erros é necessário conhecer os principais tipos de erros que são introduzidos nos mapas de produtividade, o monitor e a colhedora utilizada. Ao verificar os principais erros, Menegatti e Molin (2003) desenvolveram um método pra sua retirada utilizando um Algoritmo, desenvolvido para o mesmo. Dessa forma Menegatti e Molin (2003) obtiveram uma melhora nos mapas. O Algoritmo é exemplificado a seguir:

SE

$(\mathrm{N}(\mathrm{i})<0$ E $\mathrm{N}(\mathrm{i}-1)<0$ E N(i-2) $<0$ E N(i-3) $<0$ E N(i-4) $<0)$

$\mathrm{OU}$

$(\mathrm{N}(\mathrm{i})>0$ E N(i-1) $>0$ E N(i-2) $>0$ E N(i-3) $>0$ E N(i-4) $>0)$

ENTÃO

$\mathrm{M}(\mathrm{i})$

CASO CONTRÁRIO

SE $(\mathrm{N}(\mathrm{i})>0$ E N(i-1) $>0$ E N(i-2) $>0$ E N(i-3) $>0 ; \mathrm{N}(\mathrm{i}-4)>0)$

OU

$(\mathrm{N}(\mathrm{i})<0$ E $\mathrm{N}(\mathrm{i}-1)<0$ E N(i-2) $<0$ E N(i-3) $<0$ E N(i-4) $<0)$

ENTÃO

$\mathrm{M}(\mathrm{i})$ 


\section{CASO CONTRÁRIO}

0

FIM

FIM

donde:

$\mathrm{N}(\mathrm{i})$ - valores de ID

M(i) - valores de produtividade

\subsection{CARACTERIZAÇÃO DAS VARIÁVEIS DE PERFIS:}

2.6.1. Caliper- $C A L I$ : Perfil que fornece o diâmetro medido ponto a ponto em toda a extensão de um poço. É um indicativo da qualidade da leitura dos perfis.

2.6.2. Diâmetro da Broca - DB: é a variável que define o diâmetro nominal da broca que perfurou determinado intervalo de poço, sendo que um poço geralmente tem diferentes intervalos perfurados com brocas de diferentes diâmetros. O DB é medido em polegadas.

2.6.3. Arrombamento de Poço - Dcali: é uma variável calculada (CALI - DB), mede o quanto o diâmetro do poço se afasta do diâmetro nominal da broca que perfurou determinado trecho. Quando essa variável tem alta frequência provoca "rugosidades" nas paredes dos poços sendo que essas irregularidades afetam a qualidade das leituras dos perfis. Essa variável é medida em polegadas

2.6.4. Profundidade - Prof: é a profundidade do ponto de leitura dentro do poço. Sua escala de medida é em metros. Seu referencial de medida, isto é, o zero, é a Mesa Rotativa (MR) da sonda de perfuração. Para ser corrigido ao Nível Topográfico basta subtrair a MR. A sua correlação com outras variáveis de perfis requer uma interpretação geológica. De forma geral a velocidade sônica das rochas (DT) e a densidade (RHOB) crescem com a profundidade em função do soterramento e consequente compactação das rochas.

2.6.5. Raios Gama - GR: É a medida da radioatividade total presente nas rochas. Este perfil é utilizado, principalmente, para separar tipos diferentes de rochas, já que as argilas apresentam elevados teores de elementos radioativos e os arenitos e carbonatos têm baixa radioatividade. Esse perfil, apesar de correr centralizado é pouco afetado pelo arrombamento do poço. Sua unidade de medida é em graus API.

2.6.6. Indução - ILD: Curva de resistividade do perfil Eletro-indução. Mede a resistividade das rochas. É aplicado para cálculo de saturação e identificação dos fluidos e correlação entre os poços. Essa variável é afetada principalmente pela variação dos fluidos presentes nos poros da rocha. É medido em ohm. Metro.

2.6.7. Densidade - RHOB: Mede a densidade das rochas. É o principal perfil para a estimativa da porosidade. Normalmente é medido em g/cm3 (grama por centímetro cúbico).

2.6.8. Sônico - DT: Mede o tempo de trânsito necessário para uma onda sonora percorrer

um pé de rocha. Esse tempo é inversamente proporcional à velocidade sônica da rocha. É utilizado para a estimativa da porosidade, do grau de compactação das rochas, das constantes elásticas da rocha, correlação entre poços, detecção de fraturas e apoio à sísmica (sismograma sintético). É medido em microssegundos por pé.

2.6.9. Vsh - Vsh: É um tipo de solo que possui grãos muito pequenos (microporos). Como os espaços entre os grãos, os poros, também são muito pequenos, eles retêm mais água.

\subsection{MATERIAIS E MÉTODOS}

A partir de observações detalhadas sobre DT em relação à Vsh decidiu criar a categorias Vsh_cat, essas categorias indicam unicamente diferentes camadas de volume de argila, a relação categoria-intervalo-camada é descrita abaixo. 
o Categoria Vsh_cat $=1 \rightarrow[0 ; 0.25)$ de Vsh $\rightarrow$ camada de arenito

o Categoria Vsh_cat $=2 \rightarrow[0.25 ; 0.5)$ de Vsh $\rightarrow$ camada de arenito argiloso

o Categoria Vsh cat $=3 \rightarrow[0.5 ; 0.75)$ de Vsh $\rightarrow$ camada de folhelho arenoso

o Categoria Vsh_cat $=4 \rightarrow[0.75 ; 1)$ de Vsh $\rightarrow$ camada de folhelho

Com a construção da categoria Vsh_cat foi feita uma filtragem nas bordas da camada, ou seja, eliminando os pontos amostrados nos extremos de todas as camadas, isto é os valores abaixo de 0 e acima de 1 . Seguindo a literatura, foram eliminados os valores das bordas das camadas com distancia menor que 0,53 metros, aplicando essa metodologia retiramos a interferência nos dados de DT causado pela transição das camadas de Vsh.

Vsh: É um tipo de solo que possui grãos muito pequenos (microporos). Como os espaços entre os grãos, os poros, também são muito pequenos, eles retêm mais água.

Na observação da relação de DT e Dcali a analise separou-se em dois casos, o de interferênciade DT causada pela variação alta e brusca de Dcali e a hipótese de um ponto de corte acima de uma polegada.

Arrombamento de Poço (Dcali): é uma variável calculada (CALI - DB), mede o quanto o diâmetro do poço se afasta do diâmetro nominal da broca que perfurou determinado trecho, esse valor é chamado de "arrombamento do poço". Quando essa variável tem alta frequência provoca "rugosidades" nas paredes dos poços sendo que essas irregularidades afetam a qualidade das leituras dos perfis, principalmente os perfis que correm com sapatas de contato junto as paredes dos poços como o perfil de Nêutrons e o Densidade. Essa variável é medida em polegadas (RUSSO, 2010).

No caso da variação brusca foi usado o modulo da derivada discreta de Dcali que discriminou os valores de DT com derivada maior que 0.10106, os dados com esse valor foram eliminados juntos com valores vizinhos com distancia de 0.35 do ponto eliminado.

Para a pesquisa do ponto de corte do Dcali foi feita uma categorização de Dcali, denominada de Dcali_cat, para indicar diferentes conjuntos de Dados de DT com valores de Dcali acima do ponto de corte. A relação categoria - intervalo de DT é representada abaixo, sendo que os pontos com Dcali maior que três polegadas foram eliminados.

o Categoria Dcali cat $=1 \rightarrow[-3 ; 1]$ de valores DT

o Categoria Dcali_cat $=2 \rightarrow(1 ; 2]$ de valores DT

o Categoria Dcali_cat $=3 \rightarrow(2 ; 2.5]$ de valores DT

o Categoria Dcali_cat $=4 \rightarrow(2.5 ; 3]$ de valores DT

O estudo aqui desenvolvido restringiu-se na categoria indicativas de camada de folhelho, pelo fato que nas camadas de folhelhos é onde ocorre a maioria dos arrombamentos. Para cada categoria de Dcali eliminou seus extremos utilizando o mesmo raciocínio do efeito de camada adjacente e construíram-se estatísticas descritivas. Com base nos resultados apresentados pelas estatísticas descritivas, foi feita uma comparação, utilizando testes estatísticos, entre a categoria de Dcali com ponto de corte padrão e as demais categorias, verificando as semelhanças dos seus parâmetros e suas distribuições e levando em conta as heterocedasticidades dos níveis estratigráficos.

Desenvolvemos um algoritmo que fosse capaz de realizar essa filtragem e que pudesse eliminar as observações que estivessem fora do padrão. O primeiro objetivo do programa é a analise do banco de dados e consequentemente foram implantadas as categorias do Vsh_cat e Dcali_ cat onde as mesmas têm como objetivo indicar unicamente diferentes camadas de volume de argila e indicar diferentes conjuntos de Dados de DT com valores de Dcali acima do ponto de corte respectivamente. Para o teste final do algoritmo foi utilizado o conjunto de 
dados de perfis petrofisícos do poço B onde no estudo inicial utilizou-se o seguinte vetor de variáveis (Profundidade, Nível Estratigráfico, DT, Dcali, Vsh). O algoritmo foi desenvolvido no DEV- PASCAL (anexo A).

Para o estudo foi analisado o banco de dados do poço B, onde foram tabulados em uma planilha e importados para o SAS Enterprise Guide. Utilizando os mesmos vetores variáveis do Algoritmo.

\section{RESULTADOS E DISCUSSÕES}

No poço B, Dcali e Vsh apresentam alto nível de desconcentração (CV>25\%) enquanto que DT se identifica como uma variável bastante concentrada (CV=20.926\%) (Tabela 1).

Tabela 1: Medidas de Tendência Central e Dispersão para Dcali, Vsh e DT sem filtragem.

\begin{tabular}{ccccc}
\hline & Média & DP & EP & CV(\%) \\
\hline Dcali & 83.098 & 17.389 & 0.218 & 20.926 \\
Vsh & 1.059 & 0.834 & 0.010 & 78.737 \\
DT & 0.479 & 0.309 & 0.004 & 64.563 \\
\hline \hline
\end{tabular}

A média do Vsh e DT encontram-se abaixo da mediana o que demonstra que as observações influentes estão na metade inferior dos dados. Contudo Dcali apresenta a situação inversa (média > mediana), o que demonstra que as observações influentes estão na metade superior dos dados (Tabela 2). O caso do DT que esta entre o mínimo e o $1^{\circ}$ quartil e a região entre o $3^{\circ}$ quartil e o máximo apresentam maior amplitude, enquanto que a região entre $\mathrm{o} 1^{\circ} \mathrm{e}$ o $3^{\circ}$ quartil apresenta menor amplitude. Isso demonstra que a leitura de DT internas estão mais concentradas que as regiões externas. Quanto a Vsh (que é uma variável percentual) $75 \%$ encontram-se até 86,3\%.

Tabela 2: Medidas de Posição Variáveis Dcali, Vsh e DT sem filtragem.

\begin{tabular}{cccc}
\hline & Dcali & Vsh & DT \\
\hline Mínimo & -2.397 & 0.000 & 53.563 \\
$\mathbf{1}^{\mathbf{0}}$ Quartil & 0.505 & 0.304 & 72.570 \\
Mediana & 1.418 & 0.609 & 79.675 \\
$\mathbf{3}^{\mathbf{0}}$ Quartil & 3.121 & 0.863 & 92.793 \\
Máximo & 6.906 & 1.000 & 155.408 \\
\hline
\end{tabular}

Tabela 2.2: Medidas de Posição Variáveis Dcali, Vsh e DT com filtragem.

\begin{tabular}{cccc}
\hline & Dcali & Vsh & DT \\
\hline Mínimo & -2.400 & 0.000 & 53.6 \\
$\mathbf{1}^{\circ}$ Quartil & 0.340 & 0.201 & 71.4 \\
Mediana & 0.830 & 0.517 & 77.7 \\
3 $^{\circ}$ Quartil & 1.670 & 0.738 & 91.6 \\
Máximo & 3.000 & 0.999 & 155.4 \\
\hline
\end{tabular}

Analise de gráficos.

Figura 01: DT sem filtragem. 


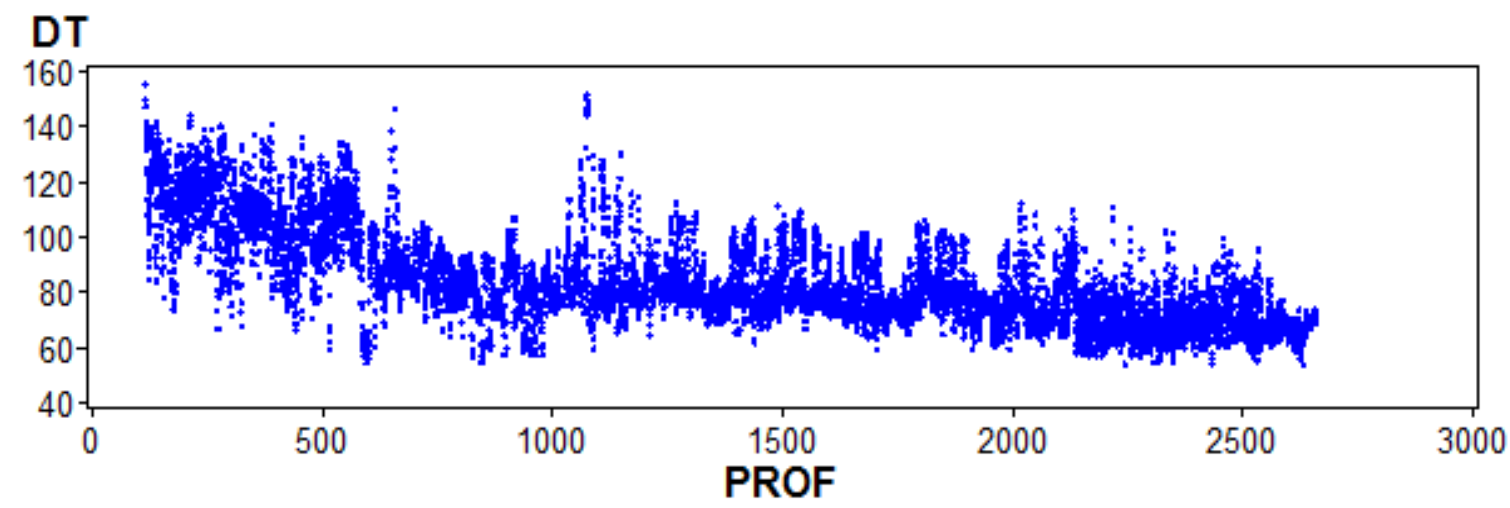

Na Figura 01 podemos observar os dados do poço B sem filtragem, na forma de gráfico. Analisando o gráfico podemos notar alguns outliers, porém o gráfico é uniforme.

Figura 02: DT com filtragem

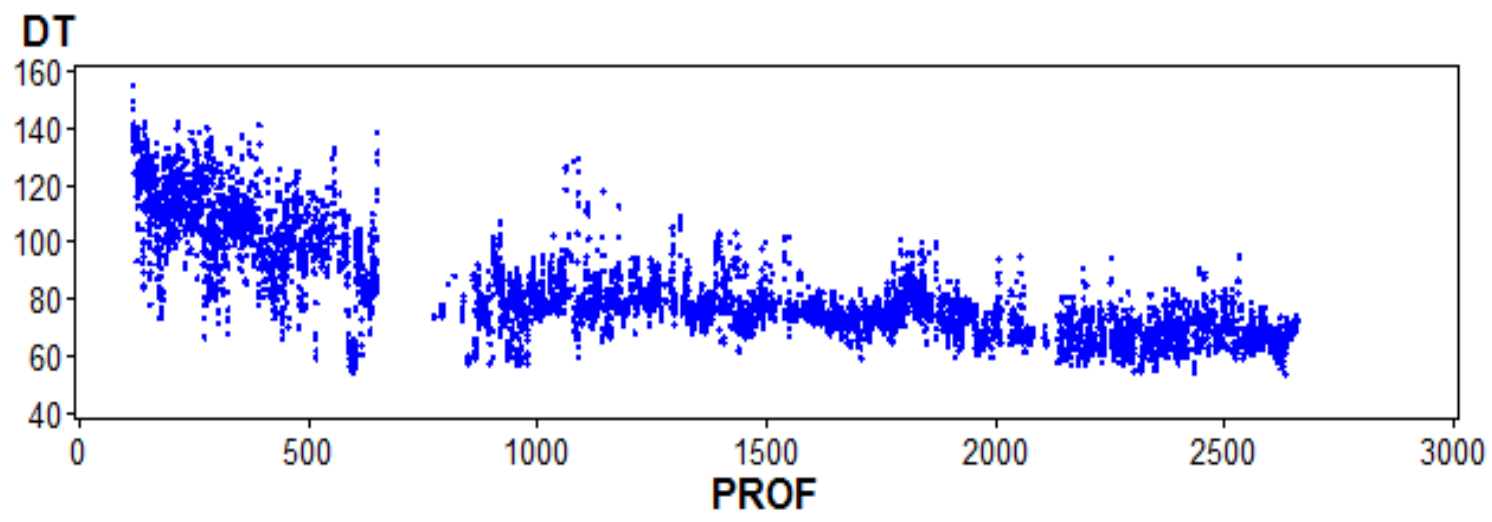

Na figura 02 constam os dados filtrados do poço B, verificamos a redução de pontos do DT e PROF podendo notar a quantidade de observações que foram eliminadas por não estarem dentro dos padrões.

Tabela 3: Número de Observações por Níveis Estratigráficos do Dcali_cat.

\begin{tabular}{ccccccccccccc}
\hline \hline & \multicolumn{10}{c}{ DCALI_CAT } \\
DADOS
\end{tabular}


A tabela 3 tem como objetivo mostrar a quantidade de observações de cada nível estratigráfico e as categorias que cada nível se classificou. Foram nomeadas como 1, 2, 3,4 e retiradas as categorias do Dcali_cat que se classificam de -3 á 1, 1 á 2, 2 á 2,5 e 2,5 á 3 respectivamente. Analisando essa tabela podemos concluir que os níveis estratigráficos que mais perderam observações foram 3P, 4B1 e 4B2 perderam 798,922 e 947 observações respectivamente, explicando a figura 2, que num ponto de 500 a 1000 da PROFUNDIDADE e de 60 a 160 do DT gera uma falha.

\section{CONCLUSÃO}

O presente trabalho propôs a criação de um algoritmo para eliminação e redução dos erros, que foi nomeado de algoritmo para redução de erros de medidas em poços de petróleo através de filtragem. Os dados foram categorizados e os Outliers, ou seja, as observações que não estavam dentro do padrão foram eliminadas dando um campo de visão melhor para a perfuração do determinado poço B.

Fazendo a filtragem dos dados foram eliminadas cerca 3841 das 10198 observações dando uma visibilidade dos poços que servem dentro das especificações necessárias para perfuração sem o risco de arrombamento.

Conclui-se o que trabalho atingiu as expectativas e visa à criação de um registro de software que poderá ser aplicado em diversas áreas com a ideia de eliminar algum tipo de anomalia.

\section{REFERÊNCIA BIBLIOGRÁFICA}

ALMEIDA, E. L. F. Dinâmica Tecnológica das Indústrias Energéticas (Apostila Didática). Instituto de Economia /UFRJ. Rio de Janeiro: Mimeo, 2002. Disponível em: <http://www.ie.ufrj.br/hpp/intranet/pdfs/apost_petroleo.pdf> Acesso em: 26 de novembro de 2012.

BAZZI, C. L. Distância entre passadas da colhedora com monitor de colheita nos mapas de produtividade e teor de água na cultura do milho. Cascavel, PR. 2007. Disponível em: < http://tede.unioeste.br/tede/tde_arquivos/1/TDE-2007-09-12T113629Z-

131/Publico/Claudio\%20Leones \%20Bazzi.pdf> acesso em: 15 de janeiro de 2013

FIGUEIRA, M. M. C. Identificação de outliers - Millenium $\mathrm{n}^{0}$. 12, Outubro, 1998. Disponível em: <http://www.ipv.pt/millenium/arq12.htm >. Acesso em: 15 de dezembro de 2012

FOX, A. J., 'Outliers in time series', Journal of the Royal Statistical Society, Ser. B, 34 (1972), 350-363.

FULLER, W.A. Introduction to Statistical Time Series, 2nd Edition. New York: John Wiley \& Sons, 1996.

PRESTELO, C. R. Aplicação do Conceito de Produção mais limpa no gerenciamento do uso da água em atividades terrestres de exploração e produção de petróleo, Salvador, BA: $2006 \quad$ Disponível em:< http://www.teclim.ufba.br/site/material_online/dissertacoes/dis_ranilson.pdf $>$ Acesso em: 02 de janeiro de 2013

FREUDENRICH, C. e STRICKLAND, J., "How Oil Drilling Works" 12 April 2001.

HowStuffWorks.com. <http://science.howstuffworks.com/environmental/energy/oildrilling.htm> 05 de fevereiro de 2013.

LIMA, K.T.P., Utilização de métodos sísmicos, perfilagem e testemunhos de poços para caracterização dos turbiditos da formação urucutuca na bacia de almada (BA), Macaé, RJ: 2005 
Disponível em: < http://pt.scribd.com/doc/58924500/Tese-Perfilagem-Kledson-TomassoPereira >

Acesso em: 10 de novembro de 2012

MARONNA, Ricardo A., MARTIN, R. Douglas, YOHAI, Víctor J., Robust Statistics Theory and Methods, 2006, John Wiley \& Sons, Ltda.

MACHADO, P.; BERNARDI, A.; SILVA, C. Agricultura de precisão para o manejo da fertilidade do solo em sistema plantio direto. Rio de Janeiro, RJ: Embrapa. 2004. Disponível em: < http://www.macroprograma1.cnptia.embrapa.br/redeap2/publicacoes/publicacoesinteressantes-sobre-ap/Livro_AP_2004.pdf\#page=72> Acesso em: 10 de dezembro de 2012

MOLIN, J. P.; GIMENEZ, L. M. Desenvolvimento de um algoritmo para redução de erros em mapas de produtividade obtidos em agricultura de precisão, Piracicaba, SP: 2000.

MENEGATTI, L. A. A.; MOLIN, J. P. Remoção de erros em mapas de produtividade via filtragem de dados brutos, Revista Brasileira de Engenharia Agrícola e Ambiental, v.8, n.1, p.126-134, 2004.

RUSSO, Suzana. Estimativa da Perfilagem em Poços de Pétroleo Utilizando a Estatística Multivariada. São Cristovão, SE: 2010. Disponível em:

$<$ http://www.ime.unicamp.br/sinape/sites/default/files/resumo\%20expandido\%5B2\%5D_0.pdf > Acesso em: 27 de novembro de 2012.

SILVA, José. Uma Plataforma para Sistemas Embarcados: Desenvolvimento e Avaliação de Desempenho de um Processador RTL e uma Cache L1 usando SystemC. Natal, RN. 2006.

Disponível: $<$ http://www.ccet.ufrn.br/prh22/trabalhos/graduacao/2006/Jose_Diego_Silva_PRH2 2_UFRN_G.pdf $>$ Acesso em: 27 de novembro de 2012.

DUARTE, O. O.,1997, Dicionário Enciclopédico Inglês-Português de Geofísica e Geologia, Sociedade Brasileira de Geofísica, 304 p.

THOMAS, J. E. Fundamentos e Engenharia de Petróleo. PETROBRAS. Rio de Janeiro: Ed. Interciência, 2001.

RUSSO, S. L.; CAMARGO, M. E.; SIMON, V. H. Avaliação De Perfis Sônicos Sintéticos Em Poços de petróleo Perfurados nas Unidades Geológicas Pertencentes a Bacia Sedimentar Sergipe-Alagoas - Brasil, 2010.

Algoritmo criado no programa Dev-Pascal.

Antes de compilar: 


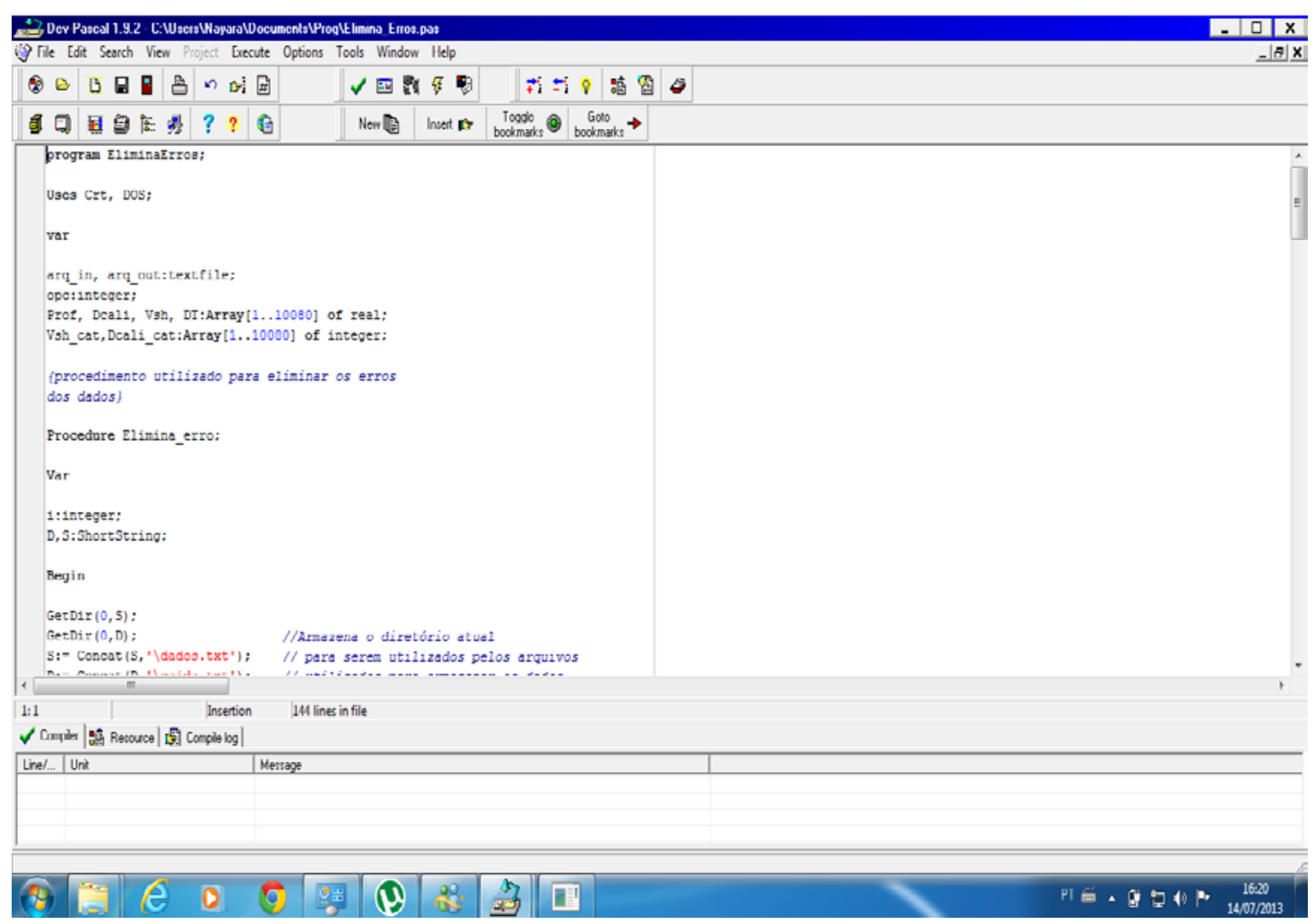

\section{Compilado:}

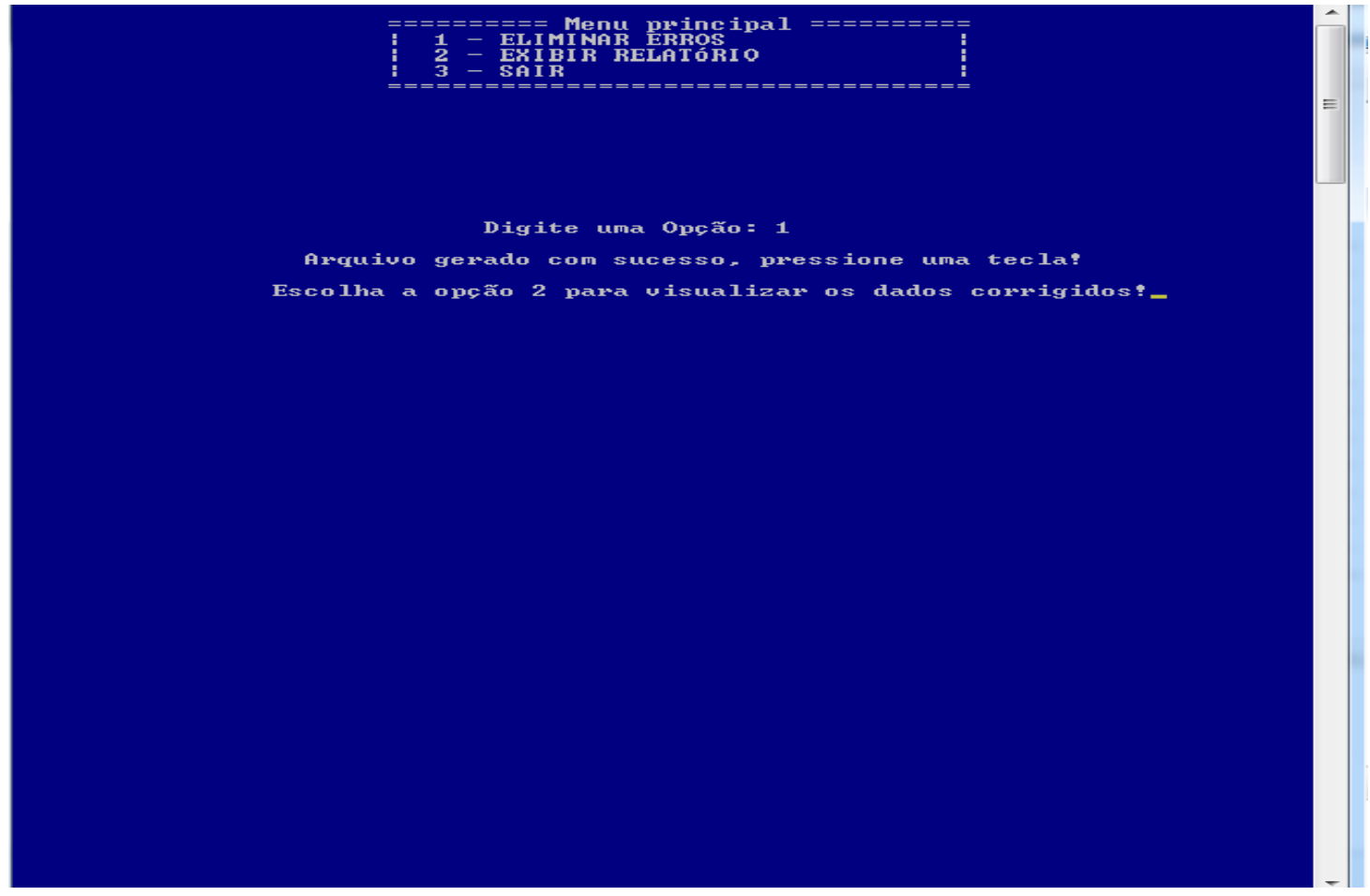

Resultados e Objetivos: 


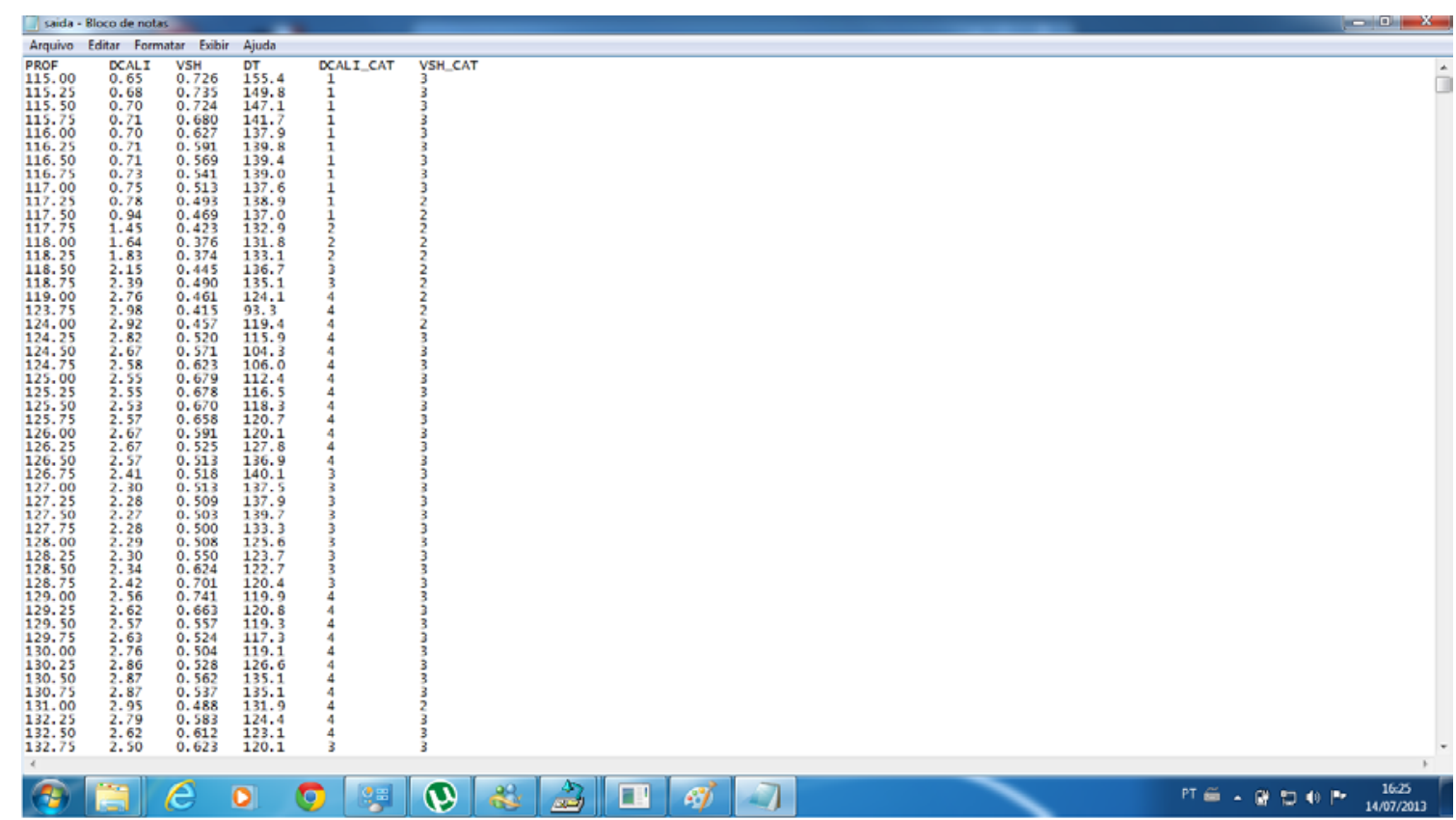

